\title{
O paleodeserto de Xique-Xique
}

\author{
AZIZ AB'SÁBER
}

$\mathrm{N}$ O BAIXO-MÉDio vale do Rio São Francisco, diante da tradicional cidade sertaneja de Xique-Xique, ocorre um grande campo de dunas quaternárias fixas que documentam a ocorrência de climas e processos eólicos de um passado relativamente recente. Feições elaboradas em um ambiente muito mais árido que os cenários climáticos e fitogeográficos hoje existentes. Em trabalhos clássicos sobre o vale do São Francisco (Derby, Teodoro Sampaio, Luiz Flores de Morais Rego), foram feitas referências ocasionais sobre a existência de dunas na região. Entretanto, era muito cedo para se avaliar o conjunto espacial das ocorrências e realizar interpretações paleoclimáticas e ecodinâmicas sobre o conjunto do campo de dunas regionais feições superficiais de terrenos do Quaternário, ou de componentes da estrutura superficial da paisagem.

No ano de 1958, em uma excursão sofrida pelo vale do importante rio - na companhia dos companheiros Alvanir Figueiredo e Bernardo Issler -, ao passar pelo setor do vale na subárea de Xique-Xique, identificamos imediatamente a presença de grandes dunas fixas e a sua aparente ordem de grandeza espacial. Observávamos de pronto que se tratava de dunas fixadas extensiva e homogeneamente por rasas formações herbáceas, na condição específica de psamobioma. A cor verde mais ou menos permanente (segundo informações obtidas na região) fazia grande contraste com as rústicas e esbranquiçadas caatingas ocorrentes no entorno do referido campo de dunas. Um fato que hoje se pode perceber e avaliar espacialmente utilizando imagens de satélite em falsacor existentes sobre a região. Devendo ser lembrado que imagens tomadas em épocas diferentes podem revelar os efeitos negativos de diversas atividades humanas na região. Através de diversos documentos cartográficos, desde cedo foi possível avaliar o espaço total das velhas dunas regionais, como tendo no mínimo 6.700 quilômetros quadrados de extensão, uma avaliação que de resto poderá ser reavaliada à custa de medidas feitas em imagens da região. Graças às observações interdisciplinares, realizadas sobre a área em diversas excursões, pudemos ter a certeza de que se tratava de um verdadeiro erg de um paleodeserto intemontano regional, de passado ainda incerto, situado em pleno Brasil Centro-Oriental. Note-se que o corpo principal das paleodunas estende-se principalmente desde os sopés da Serra do Estreito até a margem esquerda do São Francisco, descaindo diretamente para o leito maior do alongado curso d'água, de tal maneira que o rio, além de cruzar as caatingas baianas interiores, cruza lateralmente um remanescente inconfundível de desertos localizados do passado. Nesse sentido, é possível dizer que as grandes massas de areias ali depositadas, e retrabalhadas por processos eólicos, foram trazidas de montante (rio acima), por um lento comércio de sedimentação 
fluvial, em um certo período do Quaternário Superior (Pleistoceno). Existindo na região de Camaçari, no interior colinoso do Recôncavo Baiano, dois conjuntos de dunas semilitificadas, separadas entre si por uma linha de pedras bem representativa (stone lines), pode-se pensar que as altas dunas fixas de XiqueXique tenham sido geradas em uma das fases semi-áridas do Pleistoceno Superior, em momentos em que o nível geral dos mares esteve a dezenas e dezenas de metros mais baixo.

Um fato que nos pareceu digno de nota foi a presença de três ou quatro estreitos vales atuais, recortando espaçadamente o extenso campo de dunas. Nas condições hidroclimáticas atualmente vigorantes no baixo-médio vale do São Francisco, esses pequenos cursos d'água que cruzam as dunas, na categoria de afluentes da margem esquerda do rio perene, condicionados ao ritmo dos climas semi-áridos nordestinos, são dotados de drenagem intermitente sazonária. Foram certamente weds do passado, transformados por mudanças climáticas em riachos do sertão, dotados de estreitas vazantes laterais, bem aproveitadas por limitadas atividades agrárias familiares.

$\mathrm{Na}$ ocasião em que por lá passamos, encontramos alguns roceiros da região, acocorados na beira arenosa das grandes dunas, observando a circulação de embarcações no São Francisco; talvez à espera de alguma ajuda diante de um período de estiagem por demais forte e prolongado, que reduziu as atividades produtivas ao longo dos pequenos e espaçados córregos intradunares. Uma espera dramática, porque governantes municipais e estaduais nunca tiveram nenhuma atenção para os pobres habitantes sujeitos a uma geografia humana tão sofrida. E nós - Alvanir, Bernardo e Aziz -, jovens desamparados viajando em condições deploráveis de recursos, que ajuda poderíamos dar aos pobres sertanejos silenciosos, viventes de um sertão tão rústico ambiental e socialmente falando?

Depois das observações de campo realizadas nos fins dos anos de 1950, divulgamos no interior de artigos, prefácios e palestras o resultado de nossas pesquisas pioneiras. Não abandonamos a temática por anos seguidos, utilizando todas as oportunidades eventuais para a divulgação do conhecimento. Prosseguimos no exame das feições do campo de dunas regional, em cartas topográficas mais recentes, em aerofotos e, finalmente, em imagens de satélite.

No decorrer de tais trabalhos, tivemos o desprazer de receber uma crítica absurda de um ilustre cientista, que, sem conhecer a região, disse que as dunas referidas por Ab'Sáber deveriam ser apenas pequenas acumulações de areias em praias de estiagem do Rio São Francisco; e o pior é que tempos depois de suas críticas improcedentes, ao percorrer a região do campo de dunas, escreveu alguns comentários sobre as condições ambientais áridas das referidas formações eólicas do passado recente. Mas não desfez a crítica anteriormente a nós dirigida. Para mim, esse fato foi motivo para muitas reflexões. Aprendi para sempre na minha vida de pesquisador as bizarrias das ciumeiras. E me fixei em um conhecimento eticamente importante que diz respeito ao fato de que a ciência metodicamente elaborada é inocente e correta, mas que os cientistas, segundo as peculia- 
ridades de seu temperamento, podem cometer injustiças indecorosas ou interpretações lamentáveis. Para compensar o incidente, tivemos o prazer de tomar conhecimento sobre as pesquisas de um ilustre sedimentólogo, visitante da Universidade de Recife (Jannes Markus Mabesoone, 1962 e 1984), que realizou metódicos estudos sobre as areias das dunas de Xique-Xique.

Em conversações com nosso colega e amigo fraternal Paulo Emílio Vanzollini, no momento em que estávamos perseguindo o ideário da teoria dos redutos e refúgios, lembrei a ele a necessidade de fazer pesquisas de campo na região de Xique-Xique, para verificar até onde ali existiriam documentos de fauna remanescentes de outras condições ambientais e biológicas. Por coincidência, um dos orientandos de Vanzollini - Miguel Traufout Rodrigues - foi incentivado por terceiros a realizar pesquisas de campo na região das dunas fixadas existentes na margem esquerda do Rio São Francisco, diante da cidadezinha de Xique-Xique.

As pesquisas biológicas de Miguel Rodrigues na região foram transformadas em uma tese de doutorado sobre os tropiduros ocorrentes ao sul da Amazônia. Em razão do bom resultado de seu primeiro trabalho, o autor elaborou pouco mais tarde um estudo (hoje de difícil consulta) sobre as várias espécies ocorrentes na região do campo de dunas representativo de climas mais áridos do passado recente.

Após o andamento dessas pesquisas biológicas, os estudiosos de paleoclimas quaternários, com a colaboração de Paulo Emílio Vanzollini, resolveram organizar um simpósio sobre as múltiplas questões relacionadas com o campo de dunas fixas de Xique-Xique. Nessa ocasião, pela primeira vez foi discutida a questão do paleodeserto regional (erg) de um modo mais interdisciplinar e cientificamente correto. De minha parte, nem mesmo pude recuperar os dizeres completos da minha palestra no aludido simpósio, onde foi feito um trabalho de democratização de conhecimentos, para uma pequena comunidade sedenta de saberes.

Tantos anos passados após nossa primeira excursão à região de Xique-Xique, sentimo-nos na obrigação de narrar os fatos atrás registrados. E ao mesmo tempo expor novas observações feitas sobre a região, desta vez baseados na extraordinária documentação nas imagens de satélite. No ambiente de trabalho do Instituto de Estudos Avançados da USP, ajudados pela colaboração de estagiárias dedicadas e culturalmente bem preparadas - Diana de Godoy e Elin Lutke -, fizemos a montagem de todas as pequenas quadrículas do projeto da Embrapa, intitulado "O Brasil visto do espaço", conseguindo abranger o espaço total do campo de dunas regional, desde a margem esquerda do São Francisco até a Serra do Estreito, barreira limitadora dos velhos cómoros, a dez quilômetros de distância do rio. Pela análise de tal documento compósito, pudemos verificar que existem perigosas atividades de origem antrópica que poderão afetar o psamobioma ali existente. Foi possível verificar cinco tipos de degradações: cicatrizes vivas de derruição das dunas ao norte do conjunto; trilhas anastomosadas de trânsito de bodes por extensos trechos da parte oriental das velhas dunas regionais; derruição da periferia extrema do campo de dunas no piemonte oriental da crista norte-sul da Serra do Estreito; areias expostas na beirada das dunas diante 
do leito maior do Rio São Francisco; e ampliação da devastação em alguns outros vales outrora dotados de estreitas vazantes por atividades agrárias rústicas. A intervenção infeliz de atividades agrárias no trecho norte das dunas tem uma história triste de conhecimentos científicos: alguém interessado em provar uma desertificação em processo mencionou em um trabalho publicado em Brasília que os dois subsetores de areias expostas por derruição impensada seriam documentos de um processo de aridificação atual, mal sabendo que se tratava de reativação local de velhas dunas de um deserto arenoso ali estabelecido em algum momento do Quaternário. Trata-se de outro fato que documenta a falta de documentos científicos e a aceitação da ignorância por diligentes de órgãos governamentais específicos. Pior do que isso tudo, no momento em que alguns políticos e técnicos mal preparados falam em revitalizar o São Francisco à custa de um singelo projeto de plantas beiradeiras, sem saber que as ameaças de açoreamento são muito maiores do que se pensa. Convém lembrar sempre que o campo de dunas de Xique-Xique constitui a maior massa de areias existentes em qualquer parte do território brasileiro. Trata-se de um ambiente dotado de fortíssima erodibilidade, quando impactados pela erosividade de ações antrópicas incompatíveis. De minha parte, ao voltar sofridamente a tratar de fatos referentes ao Velho Chico, quero dizer que os governante e políticos ou aprendem um pouco mais e ficam menos autoritários, agressivos e donos da verdade, ou a crônica histórica de todo um período de governo será lamentável e irrecuperável. No dia em que as autoridades ambientais específicas quiserem transformar o espaço total das velhas dunas em uma área de preservação permanente terá que haver um conjunto de propostas para compensar os pobres roceiros das vazantes, assim como os pastores de bodes que estão iniciando uma nova atividade de conseqüências gravíssimas para a derruição das dunas. Qualquer pessoa bem treinada em planejamento poderá ofertar sugestões que conciliem o ideário de preservação integrada da região com atendimento social por compensações de fácil aceitação. Por ora, é preciso que o Ministério do Meio Ambiente fique mais alertado sobre a existência de um cenário fisiográfico e ecológico tão delicado e importante. Tinha razão Dom Luiz Flávio Cappio em protestar contra a ignorância de fatos essenciais que dizem respeito às limitações de uso do solo no médio-baixo vale do São Francisco: um rio que cruza os ecossistemas das caatingas sertanejas, e por acréscimo transita pelas bordas de um paleodeserto arenoso.

Referência histórica [Nota em provas]

WILLIAMS, H. E. Notas geológicas e econômicas sobre o vale do rio São Francisco, Boletim do Serviço Geológico e Mineralógico. Rio de Janeiro, no 12, 1925.

Identificação pioneira sobre a presença de dunas desérticas no médio Vale do São Francisco. Referência bibliográfica em trabalho de Paulo C.F. Gianini et al. Dunas e paleodunas e oléicas costeiras e interiores. In: SOUZA, C. R. G. et al. Quartenário do Brasil. São Paulo: Holos, 2005. No artigo referido, existe um correto comentário sobre um trabalho de Alfredo José Porto Domingues, em que foi reconhecido o campo de paleodunas (1944). 
Imagens de Satélite: Cortesia do Autor.

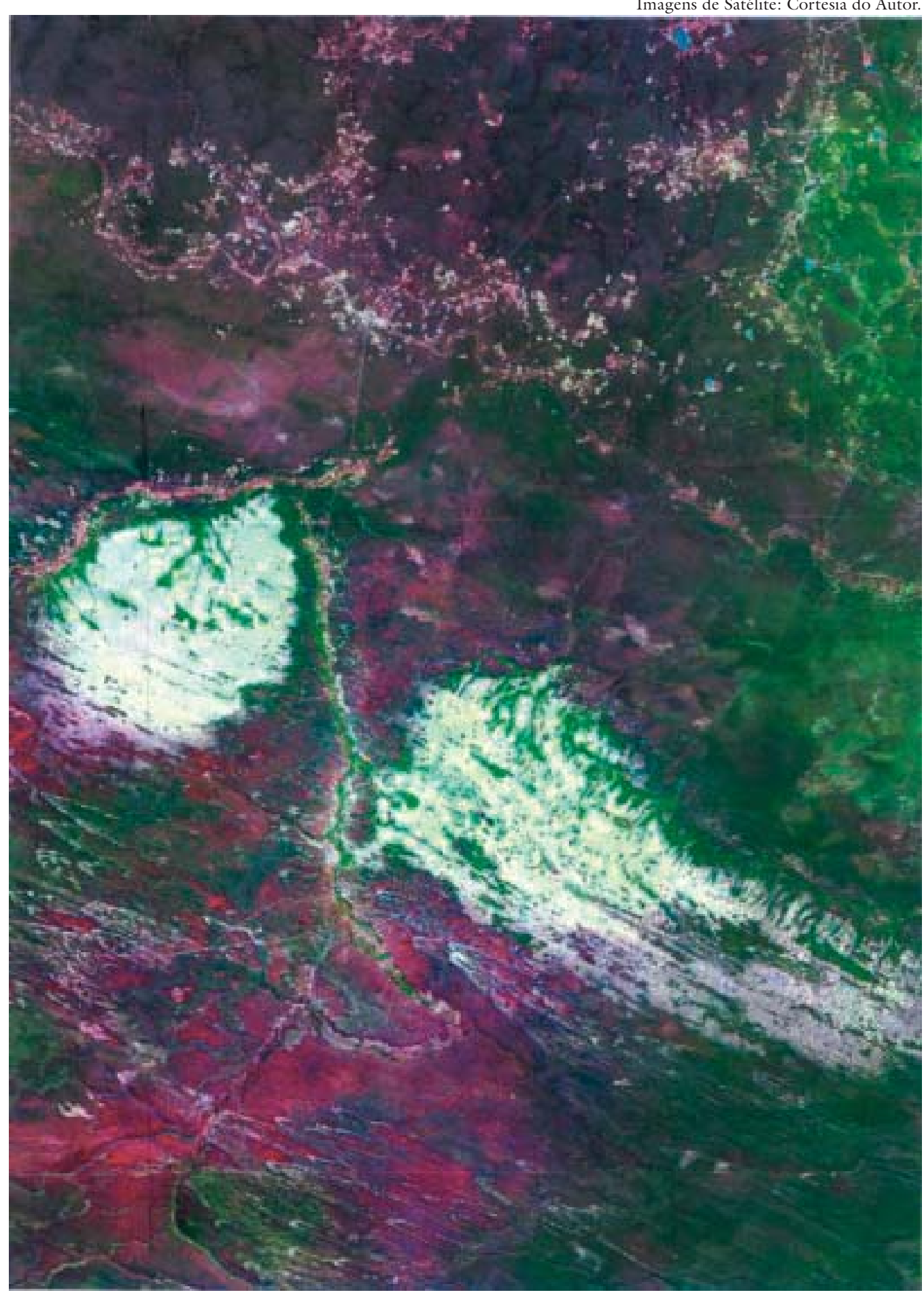

Derruição nas bordas norte do campo de dunas em razão da tentativa de utilização dos so-los arenosos, anteriormente fixados por uma selva homogênea (psamobioma). Alguém não preparado afirmou que as tais lesões constituíram um registro sobre desertificação em processo no conjunto do Nordeste seco [Escala 1: 50.000]. 


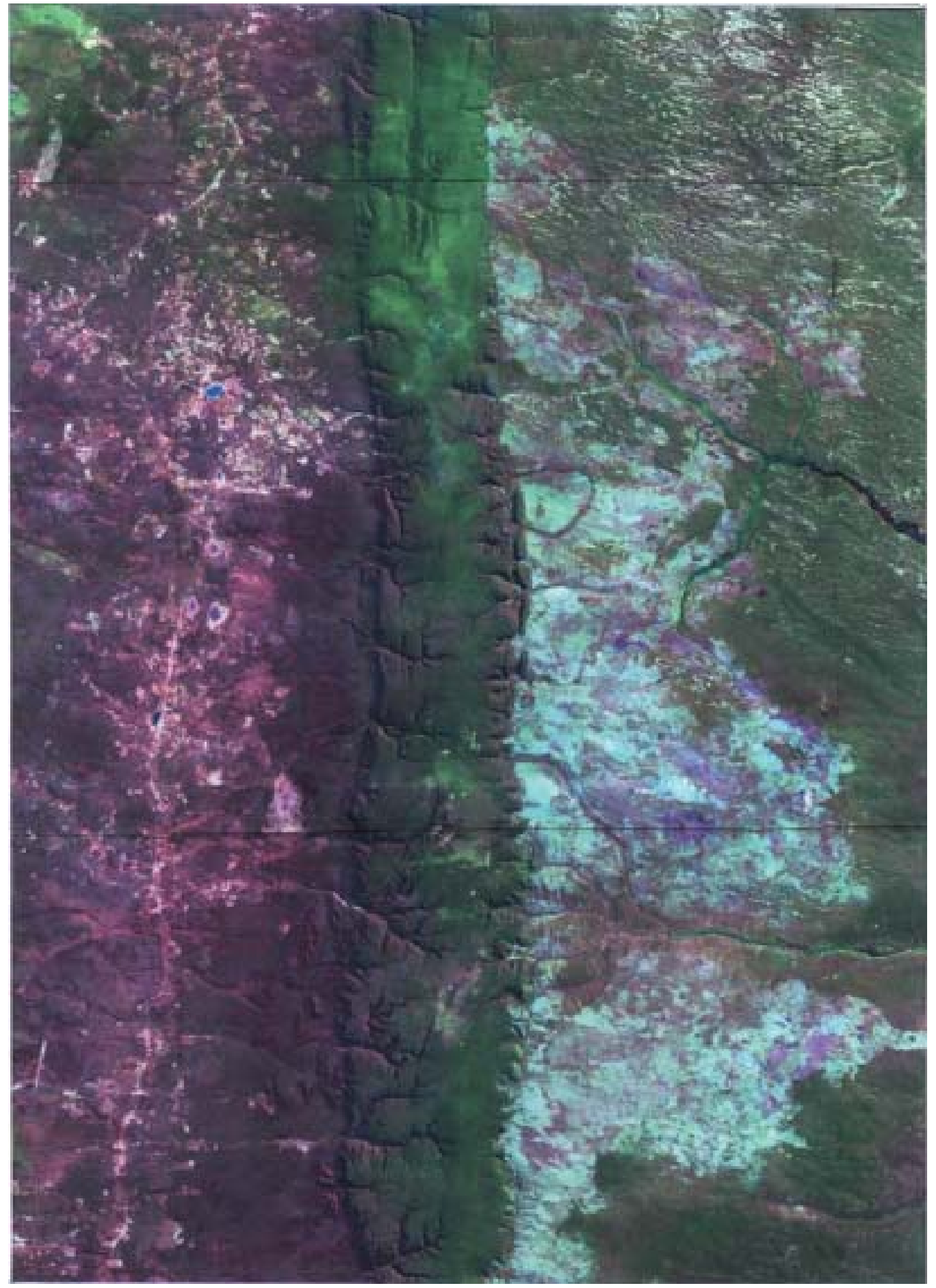

Lesionamentos no piomonte leste da Serra do Estreito em franca progressão no campo das dunas fósseis regionais. A oeste da Serra, em colinas com caatingas, o modelo de ocupação sertaneja com gente em toda parte. É de se notar o múltiplo significado desse fragmento de imagem de satélite onde existem fatos geomorfológicos, pedológicos, hidrográficos e antropogeográficos [Escala 1:50.000]. 


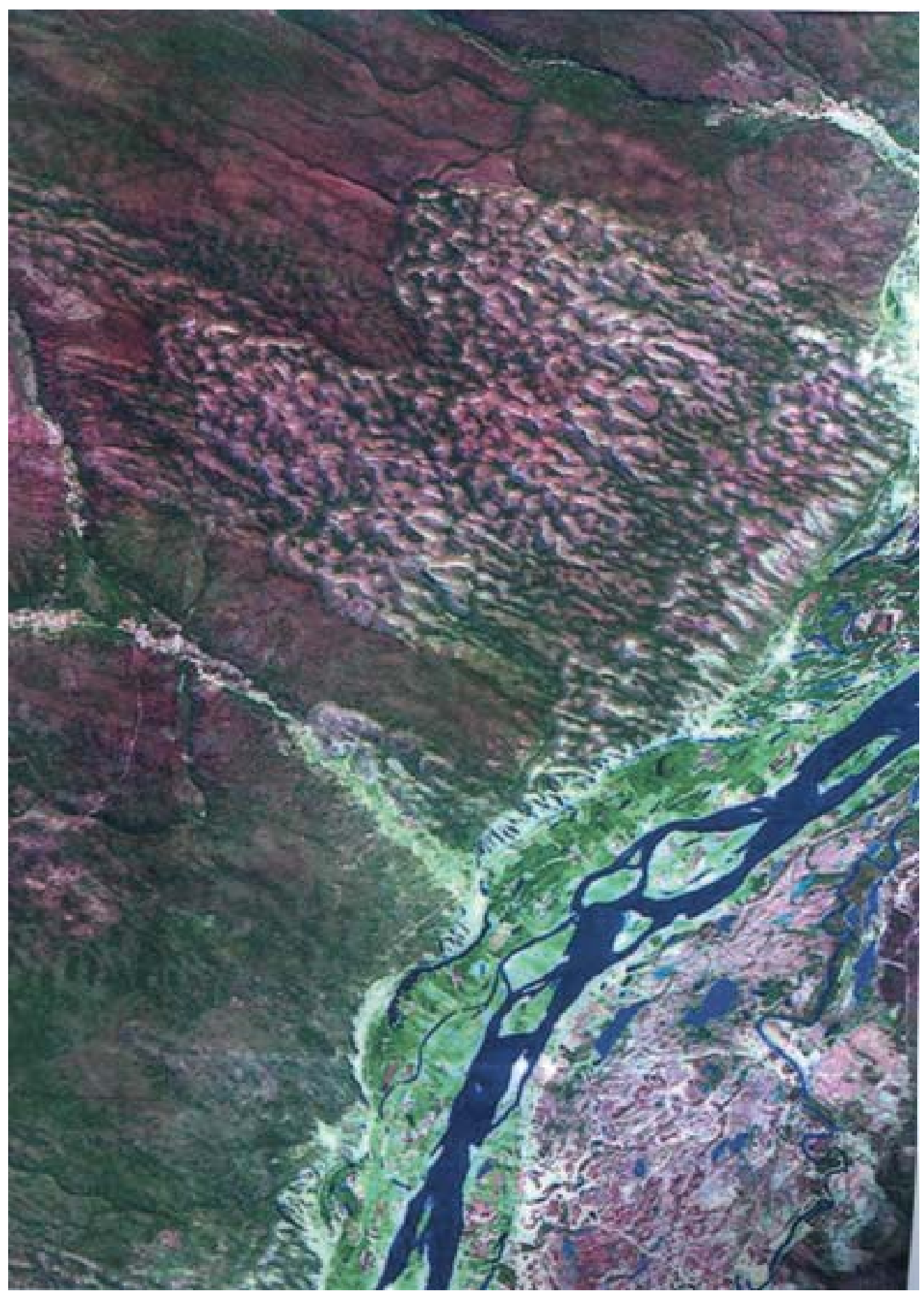

Cenário de trilhas anastomozadas de bodes na borda leste do paliocampo de dunas de Xique-Xique. A imagem de satélite registra neste segmento a progressão dos possessos inadequados de uso do solo ao mesmo tempo que mostra um trecho flúvio aluviar do Rio São Francisco, assim como culturas de vazantes na estreita faixa de um vale fluente que cruza o campo de dunas [Escala 1:25.000]. 
RESUMO - DECORRIDO quase meio século entre a identificação do campo de dunas de Xique-Xique no médio vale inferior do São Francisco, o autor retorna ao assunto, em termos de divulgação científica, e alerta para autoridades federais e estaduais brasileiras. Utilizando imagens de satélites recentes sobre a região, identificou-se o ambiente perigoso da derruição progressiva a que o paleocampo de dunas está sujeito: lesões ao norte do frágil conjunto de dunas regionais, ampliação do uso inadequado dos pequenos vales que cruzam o paleodeserto Quaternário (Pleistoceno Superior), trilhos e anastomosadas de bode de irradiação progressiva no dorso das altas dunas fixadas por vegetação rasteira homogênea (psamobioma) e ampliação das margens ocidentais do campo de dunas a partir do piemonte da Serra do Estreito. Há outras lesões em processo que podem invalidar a pretensa revitalização do Rio São Francisco.

palavras-chave: Campo de dunas, Processos eólicos, Paleoclimas, Psamobioma, Vale do São Francisco [médio vale inferior], Região de Xique-Xique, Quaternário Superior, Vegetação fixadora, Alertas/proteção.

ABSTRACT - ALMOST half century after identifying the Xique-Xique dune field in the lower middle valley of the São Francisco river, the author takes up the subject again, both as scientific disclosure and as a warning for federal and state authorities in Brazil. Using recent satellite images of the region, he identifies the dangerous environment of progressive dilapidation that the paleo dune field is subject to. One already finds lesions on the north side of these fragile regional dunes and extensive improper use of the small valleys that crisscross the Quaternary paleodesert (later Pleistocene). There is also a progressive irradiation of trilhos e anastomosadas de bode on the chine of higher dunes, fixed by homogeneous creeping vegetation (psammous biome) and an enlargement of the western boundary of the dune field (from the piedmont of the Estreito mountain range), not to mention other ongoing lesions, which may confute the alleged revitalization of the São Francisco river.

KErwords: Dune field, Aeolian processes, Paleoclimates. Psammous biome, Valley of the São Francisco river (lower middle), Xique-Xique region, Upper Quaternary, Sandtrapping vegetation, Warnings/protection.

Aziz Ab'Sáber, geógrafo, é professor honorário do Instituto de Estudos Avançados da USP. @-absaber@usp.br

Recebido em 2.2.2006 e aceito em 6.2.2006. 